\title{
La potencial contribución del Plan Regulador Territorial frente al desastre en la Ciudad de Upala, Provincia de Alajuela, Costa Rica, asociado al paso del Huracán Otto
}

\author{
The potential contribution of the Territorial Regulatory Plan to \\ offset the disaster take place in the City of Upala, Province of \\ Alajuela, Costa Rica, associated with the passage of \\ Hurricane Otto
}

Gustavo Barrantes-Castillo ${ }^{I}$

Universidad Nacional, Costa Rica

Luis Fernando Sandoval-Murillo

Universidad Nacional, Costa Rica

Max López-López ${ }^{5}$

Universidad Nacional, Costa Rica
José Francisco Valverde-Calderón ${ }^{2}$

Universidad Nacional, Costa Rica

Arvin Romero-Romero ${ }^{4}$

Universidad Nacional, Costa Rica

Annie Vargas-Hernández ${ }^{6}$

Secretaría Técnica Nacional

Ambiental, Costa Rica

1 Doctor en Ciencias Naturales, profesor e investigador en la Escuela de Ciencias Geográficas. Universidad Nacional, Costa Rica. Correo electrónico: gustavo.barrantes.castillo@una.cr.

(D) https://orcid.org/0000-0003-2130-8883

2 Ingeniero topógrafo, profesor e investigador en la Escuela de Topografía Catastro y Geodesia. Universidad Nacional, Costa Rica. Correo electrónico: jose.valverde.calderon@una.ac.cr.

(iD https://orcid.org/0000-0003-3926-1761

3 Máster en Sistemas de Información Geográfica y Teledetección, profesor e investigador en la Escuela de Ciencias Geográficas. Universidad Nacional, Costa Rica. Correo electrónico:luifersandoval@gmail.com (iD https://orcid.org/0000-0002-8325-1117

4 Estudiante de licenciatura, Escuela de Ciencias Geográficas. Universidad Nacional, Costa Rica. Correo electrónico:arvin.romero@gmail.com. (D) https://orcid.org/0000-0003-2017-713X

5 Máster, profesor e investigador en la Escuela de Historia. Universidad Nacional, Costa Rica. Correo electrónico:maximilian.lopez.lopez@una.cr. (Dhttps://orcid.org/0000-0003-3175-1731

6 Máster en Gestión del Riego, funcionaria de la SETENA y profesora en la Escuela de Ciencias Ambientales, UNA. Universidad Nacional, Costa Rica. Correo electrónico:avahe08@gmail.com

(iD https://orcid.org/0000-0003-0670-5805 
Gustavo Barrantes-Castillo José Francisco Valverde-Calderón Luis Sandoval-Murillo Arvin Romero-Romero The potential contribution of the Territorial Regulatory Plan to offset the disaster take place in the City of Upala, Province of Alajuela, Costa Rica, associated with the passage of Hurricane Otto

\title{
Resumen
}

Se ha especulado en los programas de opinión sobre los beneficios que pudo haber tenido el Plan Regulador del Cantón de Upala, elaborado por la Escuela de Ciencias Geográficas de la Universidad Nacional, de haber sido aprobado unos años antes del paso del huracán Otto. En el presente artículo se describen los alcances que dicho plan tenía en materia de restricción del uso de suelo en la zona consideradas inundables, no sin antes hacer un análisis histórico ambiental de la relación de la comunidad de Upala con el río Zapote. Adicionalmente, por medio del levantamiento de evidencias en campo y el uso de Sistemas de Información Geográfica, fue posible reconstruir las alturas del agua y relacionar su comportamiento con la distribución de la ciudad y las previsiones hechas en el Plan Regulador. Los resultados indican que el comportamiento de este evento extremo no fue previsto, lo que provocó un fuerte impacto sobre áreas que habían sido zonificados como de uso residencial e institucional. Esta experiencia invita para reflexionar sobre la necesidad de considerar el cambio climático en la planificación territorial.

Palabras clave: Gestión del Riesgo, Inundaciones en Upala, Huracán Otto, Ordenamiento Territorial.

\begin{abstract}
There has been speculation among public opinion television programs regarding the hypothetical benefits that the proposed Territorial Regulatory Plan of the canton of Upala, prepared by the School of Geographical Sciences of the Universidad Nacional, could have had if it had been approved a few years before the passage of Hurricane Otto. This article describes the scope that said plan had in terms of restricting land use in the then considered flood susceptible areas, but not before performing a historical environmental analysis of the relationship existing between the community of Upala and the Zapote River. Additionally, through the gathering of field evidence and the use of geographic information systems (GIS), it was possible to reconstruct reached water levels and relate flooding behavior to the city's distribution and the forecasts made in the Territorial Regulatory Plan. Results indicate that the behavior of this extreme natural event was not foreseen thus causing a strong impact in areas previously zoned and approved for residential and governmental use. This experience invites to reflect on the need to consider climate change in territorial planning.
\end{abstract}

Keywords: Risk management; Floods in Upala; Hurricane Otto; Land management.

\section{Introducción}

El 23 de noviembre de 2016 se produjeron ráfagas de convección profunda en el centro de la tormenta tropical denominada Otto, lo que llevó a esta a convertirse en un huracán con el mismo nombre cuando se encontraba en el Mar Caribe, a unos $150 \mathrm{~km}$ al este de la frontera entre Costa Rica y Nicaragua.

Poco después, se produjo un período de rápida intensificación mientras comenzó a moverse velozmente hacia el oeste. Otto alcanzó su 
intensidad máxima con velocidades del viento estimadas de $185 \mathrm{~km} / \mathrm{h}$ a las 1200 UTC, cuando se encontraba a unos $40 \mathrm{~km}$ al este de la frontera entre Costa Rica y Nicaragua. Continuó avanzando hacia el oeste y tocó tierra en la Reserva Biológica Indio Maíz, en el extremo sur de Nicaragua, aproximadamente a $16 \mathrm{~km}$ al noroeste de la frontera entre Nicaragua y Costa Rica, con categoría 3 en la escala Saffir-Simpson (Brown, 2017).

El huracán ingresó a Costa Rica a las 2:00 pm del jueves 24 de noviembre, a $4 \mathrm{~km}$ al este del poblado las Delicias. De acuerdo con la trayectoria de su centro, pasó por los distritos de Los Chiles y Caño Negro (cantón de Los Chiles), luego por Yolillal, Upala, San José y Aguas Claras (cantón de Upala). A las 6 pm, estando en Yolillal de Upala, fue declarado huracán categoría 1, posteriormente pasó por los distritos de Cañas Dulces, Mayorga y Nacascolo (cantón de Liberia). A las 9 pm fue degradado a tormenta tropical cuando se encontraba a $22 \mathrm{~km}$ al norte de la ciudad de Liberia.

Este sistema abandonó el país a las 10:30 pm del 24 de noviembre en los alrededores de playa Naranjo en el Golfo de Papagayo (Instituto Meteorológico Nacional, 2017) (Mapa 1).

Otto es considerado el primer huracán con impacto directo en el país al menos desde 1851. A su paso generó aguaceros torrenciales con acumulados diarios de $300 \mathrm{~mm}$ y vientos intensos con ráfagas de 15 a $30 \mathrm{~m} / \mathrm{s}$ al norte del país (Instituto Meteorológico Nacional, 2017).

A su paso por el territorio nacional generó una afectación directa a 10.831 personas (en 461 poblados) de los cuales 7.425 requirieron la atención en albergues, así como 10 muertes en el cantón de Upala y Bagaces. Las pérdidas económicas fueron estimadas en 106 mil millones de colones, la mayoría de los cuales se concentraron en el cantón de Upala (Comisión Nacional de Emergencias, 2017).

Las autoridades nacionales y locales, así como la comunidad, conocían que la ciudad de Upala se asentaba en el área inundable por el río Zapote. Tanto Upala como la población de Canalete cuentan con un amplio historial de inundaciones ya que su asentamiento se dio en terrenos de muy baja altitud y próximos a la confluencia de cursos fluviales. 
Gustavo Barrantes-Castillo José Francisco Valverde-Calderón Luis Sandoval-Murillo Arvin Romero-Romero

The potential contribution of the Territorial Regulatory Plan to offset the disaster take place in the

City of Upala, Province of Alajuela, Costa Rica, associated with the passage of Hurricane Otto

Mapa 1. Recorrido del Huracán Otto por Costa Rica.

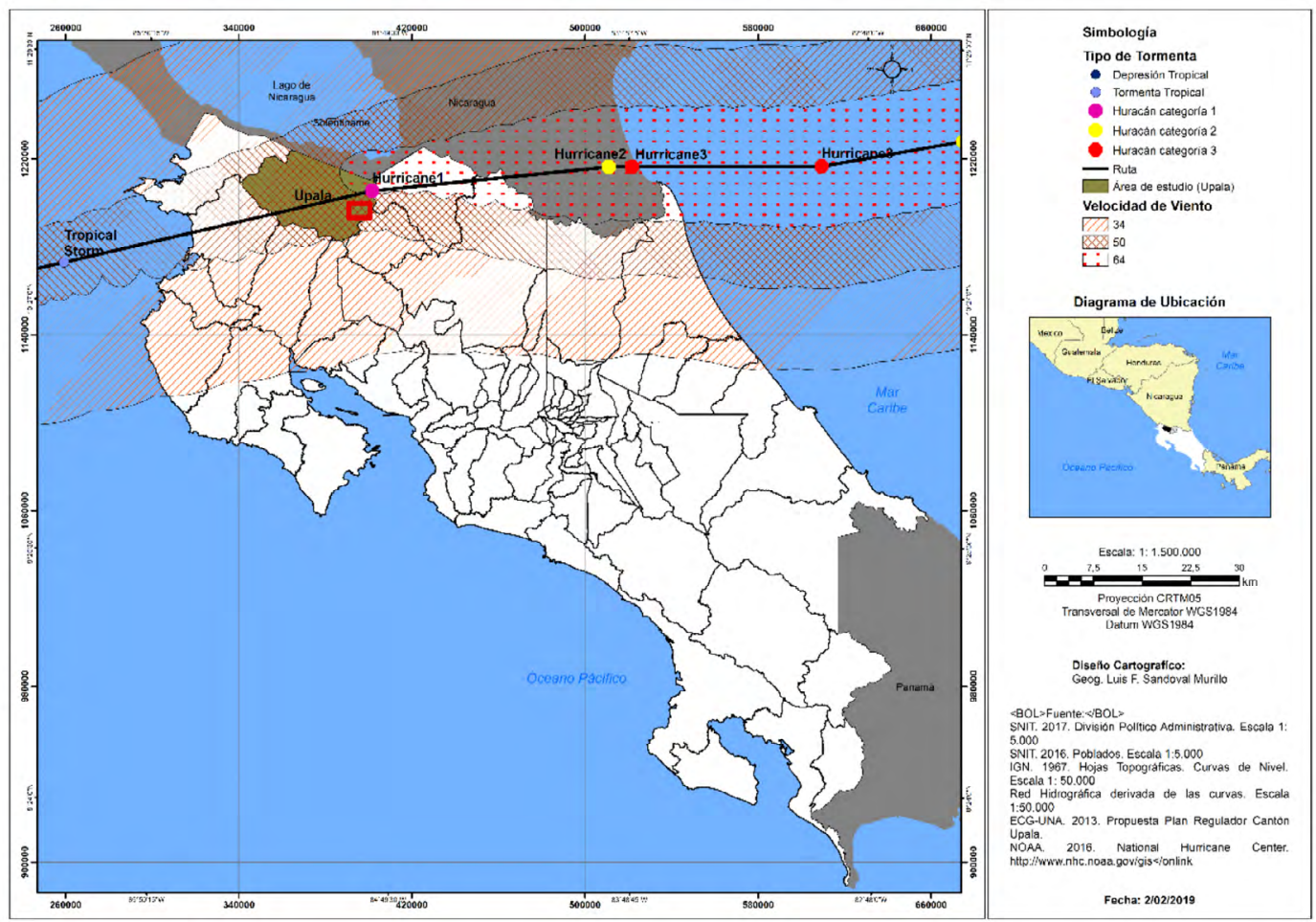

Fuente: Elaboración propia

Otros poblados importantes como San José de Upala y Cuatro Bocas también presentan inundaciones constantes, en este caso ocasionadas con el río Niño (Pizote), mientras que, en Las Brisas, Moreno Cañas y Santa Clara son resultado del desbordamiento del río Guacalito.

Las afectaciones del paso del huracán Otto sobre la ciudad de Upala son un caso interesante de estudio debido a la existencia de un plan de ordenamiento territorial, conocido en Costa Rica como Plan Regulador.

Según se planteó en los medios de comunicación en aquel momento, de haberse aprobado y ejecutado dicho plan, se pudo haber reducido el impacto de las inundaciones sobre la ciudad.

No obstante, no se había realizado el ejercicio de contrastar lo sucedido con lo previsto en plan, de manera que se pueda evaluar el aporte potencial que un instrumento como este puede tener en la gestión del riesgo, 
Gustavo Barrantes-Castillo José Francisco Valverde-Calderón Luis Sandoval-Murillo Arvin Romero-Romero La potencial contribución del Plan Regulador Territorial frente al desastre en la Ciudad de Upala, Provincia de Alajuela, Costa Rica, asociado al paso del Huracán Otto

especialmente en comunidades como Upala que nacieron y se han extendido junto al cauce de un río. Esto último, es necesario tenerlo en cuenta pues existe un condicionante histórico que no puede obviarse.

\section{La ocupación de las riveras de los ríos}

Desde la antigüedad la población buscó sitios adecuados para asentarse y desarrollar sus actividades de subsistencia, reproductivas y más tarde comerciales. En esta búsqueda de lugares, el ser humano privilegió la construcción de aldeas o pueblos, temporales o permanentes, en la rivera de los ríos o cerca de las costas.

Los cursos de agua, así como costas y lagos o lagunas se constituyeron en un factor decisivo gracias a que de ellos se obtenía agua para el consumo y alimento, pero especialmente porque se constituían en las principales rutas para el desplazamiento humano y para el transporte de diversos bienes.

El ejemplo clásico de esta simbiosis entre ríos y establecimiento de sociedades humanas lo fue la región de Mesopotamia, tierra que vio florecer varias naciones entre los ríos Tigris y Éufrates?.

Pero también, se puede señalar como ejemplos el río Nilo en África, cuna del imperio egipcio, así como el Amazonas, afluente de vida para innumerables pueblos autóctonos del sur del continente americano.

Durante el desarrollo de la Edad Media en Europa, pero especialmente con el florecimiento del comercio hacia el final de ese periodo (siglo $\mathrm{XV}$ ), cobró auge el transporte de productos por vía fluvial y marítima.

Así, surgieron algunas ciudades cerca de los principales ríos y otras se consolidaron como nodos del comercio regional. Incluso algunas grandes ciudades costeras o ribereñas se constituyeron en puntos clave del comercio internacional. Producto de esta evolución histórica, hoy se cuenta con urbes que crecieron en la margen de importantes ríos en Europa, como por ejemplo Roma (Tíber), París (Sena), Florencia (Arno), Londres (Támesis), Viena (Danubio), Sevilla (Guadalquivir) y Colonia (Rhin), entre otros.

En América, tras el proceso de colonización impulsado tanto por españoles, como por portugueses e ingleses, también florecieron ciudades

7 Aunque se les denomina sociedades hidráulicas por su desarrollo y dominio sobre el agua, en este caso no interesa realizar una diferenciación histórica-conceptual sobre modelos de desarrollo implementados por cada sociedad. 
majestuosas a orillas de grandes y caudalosos ríos como por ejemplo Nueva York (Hudson), Filadelfia (Delaware), Buenos Aires y Montevideo (de La Plata), o ciudades costeras como Río de Janeiro (Brasil) y Panamá, que además fue un punto neurálgico para el comercio colonial.

Fue práctica común de las expediciones coloniales en América, la fundación de pueblos o ciudades costeras, algunas de las cuales solo tenían como objetivo servir al aprovisionamiento de alimentos y de esclavos para las tareas de colonización del interior. Sin embargo, desde 1526 el rey Carlos $\mathrm{V}$ definió por medio de una ordenanza, algunos aspectos que se debían acatar al fundar nuevos pueblos (Martínez,1967, p.46)

"Procuren tener el agua cerca, y que se pueda conducir al pueblo y heredades, derivándola si fuere posible, para mejor aprovecharse de ella, y los materiales necesarios para edificios, tierras de valor, cultura y pasto, con que excusarán el mucho trabajo y costos que siguen de la distancia, en caso de edificar a la ribera de algún río, dispongan la población de forma que saliendo el sol de primero en el pueblo que en el agua" (Martínez,1967, p.46).

Una vez consolidada la conquista del territorio americano, pero especialmente después de la independencia y la instalación de los Estados Nacionales (hacia la década de 1870), las naciones recién formadas se dieron a la tarea de impulsar los procesos de ocupación de sus territorios con el fin de poner a producir las tierras incultas, pero también de asegurar presencia en el territorio ante eventuales invasiones dada la dificultad para establecer límites entre las jóvenes naciones.

De hecho, Costa Rica fijó sus límites con Nicaragua hasta en 1858 (ratificado en 1888) y con Panamá en 1941. Ahora bien, en este proceso de construcción social del espacio, el ser humano ha hecho uso de los ríos de distintas formas afectando sus regímenes, cursos, pureza, entre otros, a la vez que se expone a un peligro constante por inundación, que se materializa en un desastre al ocurrir un evento extremo (como es el caso durante el paso de huracanes) y que amenaza con aumentar su peligrosidad con el Cambio Climático.

\section{Metodología}

La metodología seguida se divide en cinco partes que se describen a continuación: 
1. Se analiza la relación histórico-geográfica del río con la comunidad de Upala, por medio de la revisión de hechos históricos relacionados con el río y su interpretación desde un enfoque de historia ambiental.

2. Se realiza un análisis de los alcances del Plan Regulador, elaborados por la Escuela de Ciencias Geográficas de la UNA, en relación con la zonificación de usos de suelo propuesto, en particular de la zona denominada "Zona de Riesgo de Inundación (ZRI)" y sus implicaciones en la restricción del uso del suelo. En esta etapa se revisa la ocupación que en aquel momento se presentó en la zona propensa a inundación según los estudios que sustentan este plan.

3. Se realiza un levantamiento en campo de la altura de agua a partir de las marcas dejadas por la inundación asociada con el paso del huracán Otto por la ciudad y barrios próximos. Para esto se efectúan dos campañas de medición, en todos los casos la altura máxima del agua durante la inundación fue determinada a partir de las marcas dejadas en las edificaciones, utilizando una cinta métrica (Figura 1). A continuación, se detalla cada campaña:

Figura 1: Marcas dejadas por la inundación del 24-25 de noviembre de 2016.

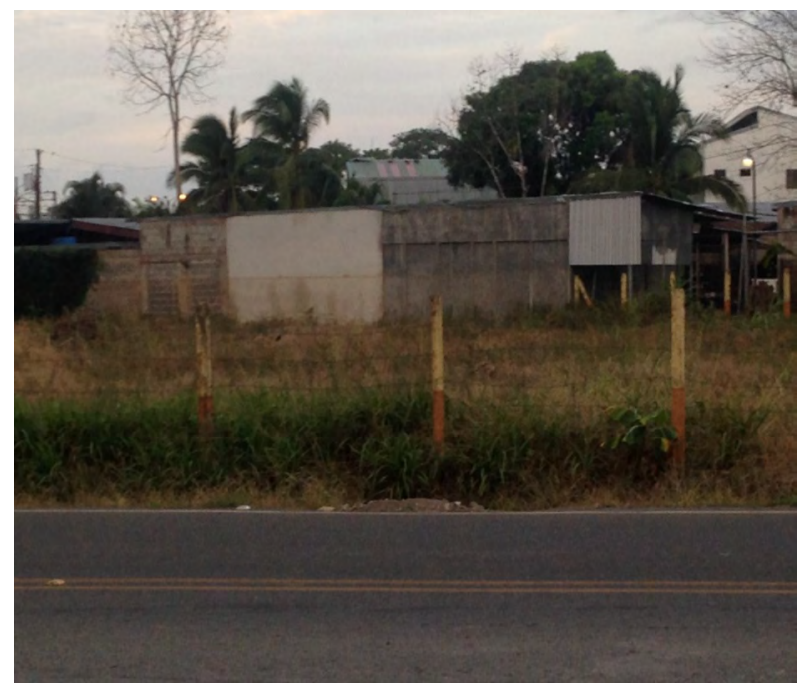

Fuente: Elaboración propia 
Gustavo Barrantes-Castillo José Francisco Valverde-Calderón Luis Sandoval-Murillo Arvin Romero-Romero The potential contribution of the Territorial Regulatory Plan to offset the disaster take place in the City of Upala, Province of Alajuela, Costa Rica, associated with the passage of Hurricane Otto

(a) En la primera campaña, se contó con un Sistema de Posicionamiento Global (GPS) navegador con un margen de precisión de $\pm 6 \mathrm{~m}$ y un Sistema de Posicionamiento Global Diferencial (DGPS) con una precisión subcentimétrica, ambos equipos fueron utilizados para determinar las coordenadas geográficas de las alturas del agua medidas con cinta métrica. Con el GPS navegador se ubicaron y levantaron las marcas dejadas sobre edificaciones públicas: Escuela Teodoro Picado, Parque Central, Cruz Roja, Palacio Municipal, Delegación de Policía, Estación de Bomberos, Salón Multiuso, Escuela Náhuatl de atención prioritaria y la Escuela recién construida. Con el DGPS se realizó un barrido registrando las marcas dejadas en las edificaciones a las orillas de la carretera procurando tener un eje de norte a sur y de este a oeste que abarcara la ciudad.

(b) En la segunda campaña, realizada seis meses después del evento, se utilizó un GPS para densificar la toma de datos por la ciudad (Mapa 2).

4. En la cuarta etapa, los datos fueron interpolados para establecer líneas de igual altura de agua, por medio de la herramienta de geo estadística del ArcGis 10.6 usando el método de kriging . Al resultado se le realizó una corrección manual tomando en cuenta el modelo de elevación del terreno generado con datos LiDar en 2017 que nos fue facilitado por la la CNE, de modo que tuviese una orientación física lógica en el terreno.

5. Finalmente, la información de las alturas alcanzadas por el agua de inundación fue sobrepuesta a la zonificación de usos propuestos, de modo que se pueda hacer prospección del riesgo futuro si el plan regulador hubiese sido aprobado por el municipio.

\section{Ubicación del área de estudio}

Por medio de la Ley 4541 del 17 de marzo de 1970 se crea el Cantón de Upala y se declara Ciudad de la entonces denominada Villa de Upala, que se ubica en el distrito del mismo nombre. En la cabecera del distrito de Upala se localiza el principal centro poblado; está ubicado por las coordenadas geográficas, latitud $10^{\circ} 53^{\prime} 55.04^{\prime}$ ' N y longitud $85^{\circ} 0{ }^{\prime} 52.44^{\prime}$ ' O. La referencia cartográfica se puede consultar oficialmente en las hojas 
Gustavo Barrantes-Castillo José Francisco Valverde-Calderón Luis Sandoval-Murillo Arvin Romero-Romero La potencial contribución del Plan Regulador Territorial frente al desastre en la Ciudad de Upala, Provincia de Alajuela, Costa Rica, asociado al paso del Huracán Otto

Mapa 2. Distribución de puntos de levantamiento del nivel máximo alcanzado por la inundación.

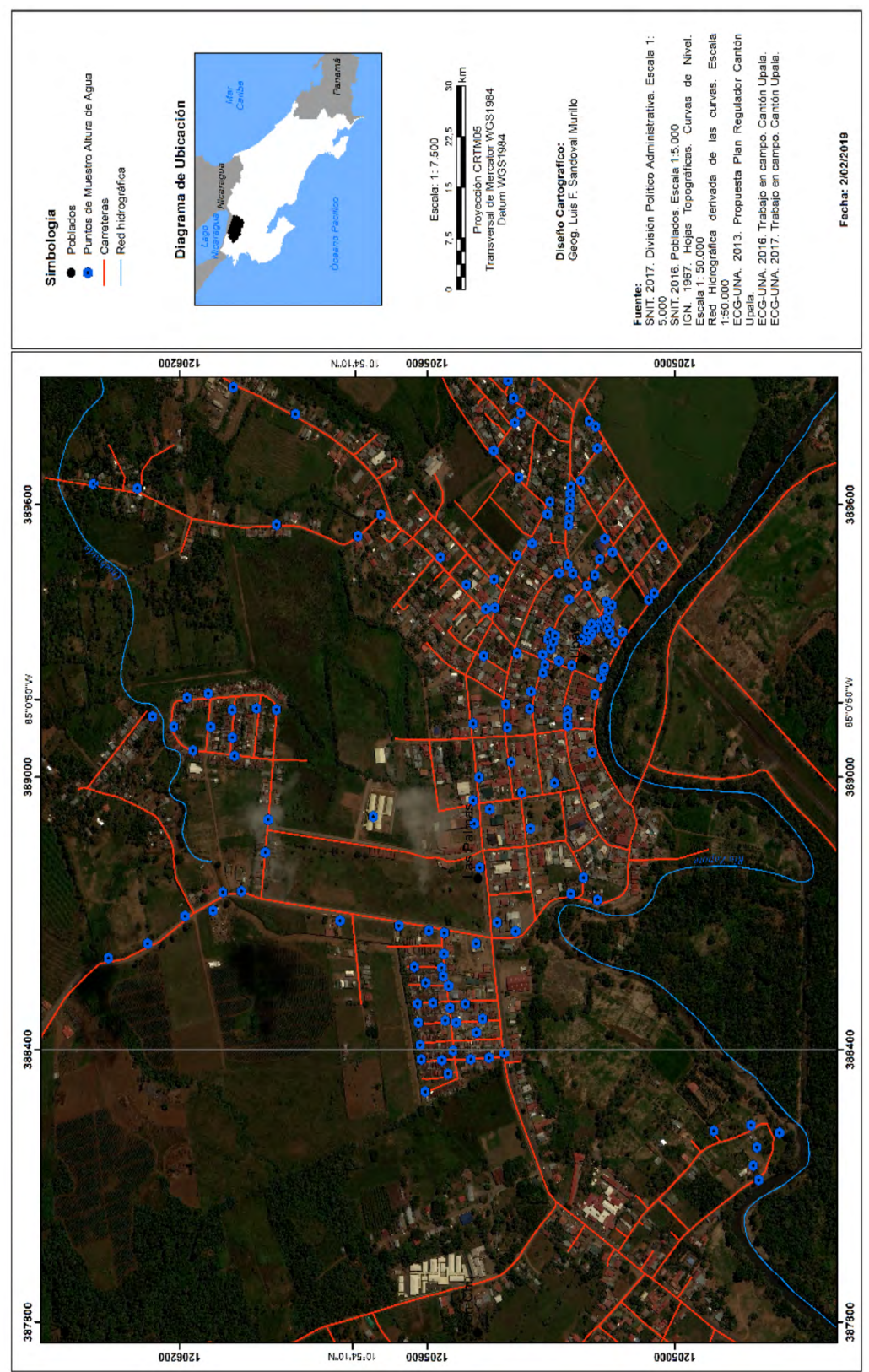

Fuente: Elaboración propia 
Gustavo Barrantes-Castillo José Francisco Valverde-Calderón Luis Sandoval-Murillo Arvin Romero-Romero

The potential contribution of the Territorial Regulatory Plan to offset the disaster take place in the

City of Upala, Province of Alajuela, Costa Rica, associated with the passage of Hurricane Otto

topográficas del mapa básico, 1:50,000 del Instituto Geográfico Nacional (IGN): Upala y Zapote.

Según datos proyectados del INEC para el 2017, el cantón de Upala cuenta con una población total de 51.930 habitantes, desagregados a nivel distrital de la siguiente manera: Upala 15.395, Aguas Claras 5.564, San José-Pizote con 8.433, Bijagua 5.184, Delicias 5.210, Dos Ríos, 3.782 y Yolillal con 3.887 habitantes.

De acuerdo con el histórico de los datos censales de los años 1973, 1984, 2000, el cantón incrementó su población en aproximadamente 10.000 habitantes por década, sin embargo, dicho crecimiento se estanca en del 2000-2009 con un crecimiento mínimo de 1.483 habitantes (ECGUNA, Plan Regulador Upala, 2012).

Upala se caracteriza por presentar un clima cálido húmedo/ muy húmedo, presentando precipitaciones comprendidas entre los 2000 - 3000 $\mathrm{mm}$ anuales en la parte baja y media del Cantón, aumentando a 3000 $4500 \mathrm{~mm}$ anuales en los sectores de mayores elevaciones. Con respecto a las temperaturas se registran valores entre $16^{\circ}$ a los $30^{\circ}$ (Hernández, 2006).

De acuerdo con el diagnóstico ambiental del plan regulador, el cantón se localiza en una formación de origen aluvial (Planicie aluvial con influencia del Lago de Nicaragua). Esta unidad geomorfológica tiene un origen netamente aluvial que está representada por un extenso territorio que se prolonga fuera del país por el norte hasta el lago de Nicaragua; tiene influencia de relleno aluvial dentro de lo que pudo haber sido el área ocupada por este cuerpo de agua en el pasado.

Se considera que la colmatación del lago, del lado costarricense se da por aportes de los ríos. Por esta razón posee una topografía plana, con un ligero declive hacia el norte que no sobrepasa $1^{\circ}$, y con ondulaciones próximas a los cursos fluviales del área.

La presencia de desniveles ha favorecido la presencia de cuerpos de agua aislados y en algunos casos cercanos a ríos tales como el río Niño (Pizote), el Guacalito y el Zapote entre otros. Algunas de estas lagunas tienen una conformación alargada por lo que sugieren que su formación obedece a los episodios de desborde de estos ríos, ya sea como cauces abandonados o pasos y depósitos efímeros de aguas en ocasión de desbordes. 
La dinámica fluvial se ajusta al transcurrir de aguas remansadas en donde los valles fluviales se ubican prácticamente a la altitud de las tierras circundantes (ECG-UNA, Plan Regulador Upala, 2012).

Las amenazas naturales presentes en el cantón de Upala, según la CNE (2003), están constituidas por inundaciones, avalanchas, caída de piroclasto (Volcán Tenorio), flujos de lodo, caída de ceniza y la presencia de fallas geológicas. De todas ellas, la inundación es la que de manera recurrente ha afectado al centro del cantón y ocasionado los mayores daños históricamente, esto por la presencia del río Zapote.

\section{Upala: un poblamiento de origen fluvial}

Luego de la independencia, pero sobre todo desde la década de 1840, los gobernantes de Costa Rica se esforzaron por impulsar el proceso de colonización del territorio costarricense, en especial mediante incentivos para desarrollar el cultivo de café.

El logro de este objetivo se alcanzó a medias y no tan rápido como los gobernantes lo hubiesen querido, entre otras cosas por la falta de vías de comunicación. Debido a ello los frentes de colonización, impulsados desde el Valle Central como un efecto centrífugo, alcanzaron apenas a regiones periféricas como Palmares, Naranjo y San Ramón por el oeste y hasta Turrialba por el este hacia la última década del siglo XIX (Hall, 1982, p.96).

Hacia las costas la apertura de caminos fue un tanto más rápido dada la necesidad de llevar la producción hasta los puertos. En este marco, tanto el sur del país como la zona norte se convirtieron en un espacio de frontera agrícola que poco a poco empezó a ser ocupada por los constantes procesos migratorios hacia la periferia, con particular fuerza en las primeras décadas del siglo XX.

Entre tanto, desde las últimas décadas del siglo XIX, en la zona norte del país se presentaba una dinámica de ocupación derivada de procesos migratorios desde Nicaragua. Según algunos estudios (Torres y Peters, 2013), las informaciones posesorias permiten establecer la ocupación de la zona de Upala, al menos desde la década de $1880^{\circ}$. La mayoría de los pobladores que llegaron a esta región procedían de diversas zonas de Nicaragua,

8 Esta región se conoció con el nombre de Zapote de Guatuso hasta 1911, año en el que mediante decreto se le cambió el nombre a Upala. 
Gustavo Barrantes-Castillo José Francisco Valverde-Calderón Luis Sandoval-Murillo Arvin Romero-Romero

The potential contribution of the Territorial Regulatory Plan to offset the disaster take place in the

City of Upala, Province of Alajuela, Costa Rica, associated with the passage of Hurricane Otto

especialmente de Rivas y San Carlos, pero no solo llegaron a Upala, sino que estuvieron presentes en los territorios de San Carlos y Sarapiquí, donde se denunció que estaban tomando como esclavos a los indígenas Maleku que habitaban esa región (Solórzano, 2005, p.12).

Los migrantes nicaragüenses que ingresaron a territorio costarricense desde el siglo XIX llegaron vía fluvial navegando por el Lago de Nicaragua y el río San Juan, sitios desde donde penetraban al territorio por medio de los ríos Zapote, Frío, San Carlos y Sarapiquí. Estas primeras incursiones estuvieron sobre todo motivadas por la explotación de hule en los bosques del norte del territorio costarricense, producto con alta demanda desde 1860 cuando se abrió el mercado de este producto para Centroamérica (Solórzano, 2005, p.13).

El hule o caucho natural era llevado a Nicaragua y de ahí exportado o vendido a compañías que lo comercializaban a escala internacional. Pero además de la explotación de hule los visitantes se llevaban consigo otros recursos tales como peces (de la actual zona de Caño Negro de los Chiles), maderas y palmas.

Sin embargo, la variación del precio del hule por un lado y el reconocimiento del territorio por otro hicieron que los nicaragüenses que llegaban a la zona de Upala se empezaran a quedar en la región. Según Chinchilla (1987, p.156) estos migrantes empezaron a establecerse, "próximos a las vías navegables que se comunican con el Lago de Nicaragua, dando origen a incipientes poblados a la orilla o cerca de los principales ríos. Estos primeros colonizadores explotaron las maderas existentes y luego se dedicaron a cultivos de subsistencia" (p.156)

Con claridad, esta ubicación cerca de los ríos estaba fundamentada en la necesidad de transportar sus productos agrícolas o forestales hasta el mercado más próximo que en este caso era San Carlos, en Nicaragua. Hasta bien entrado el siglo XX, la actividad comercial de esta zona estuvo ligada a ese país y solo en lo administrativo se atendía a las disposiciones del gobierno de Costa Rica o del municipio de Grecia al que perteneció hasta 1970, la dependencia respecto al río como vía de comunicación se prolongó hasta mediados del siglo XX, aunque el camino que comunica la región de Cañas con Upala se estaba arreglando desde 1921 (ANCR, 1921). 
Al igual que ocurrió con los pueblos lineales que aparecieron a lo largo de las rutas terrestres, a lo largo del río Zapote también se crearon otros pueblos que aprovecharon la navegabilidad de esta ruta fluvial, entre ellos Canalete, Rosario, Montecristo, San Judas y San Isidro.

De este modo, la creación de pueblos y la consecuente modificación provocada por los diversos usos del suelo, especialmente la deforestación en la parte alta y media de la cuenca, empezaron a ocasionar alteraciones significativas en el caudal y el ciclo de crecidas del río Zapote. A esto se sumaron otras actividades ligadas a la extracción de piedra para lastrar caminos y de arena para construcción de diversas edificaciones.

Sumando la dinámica natural del río a las alteraciones mencionadas, desde la década de 1970 fue relativamente común que el río se desbordarse e inundara el centro de Upala, durante fenómenos atmosféricos importantes como la registrada en 1988 (huracán Juana) que afectó en su totalidad el área urbana de Upala, donde toda la población del centro (aproximadamente 5.000 habitantes) fue evacuada por el desbordamiento del río Zapote (CNE, 2012).

Y aunque posterior a este evento se construyó un dique, en la década de los 90, el mismo no ha podido contener las inundaciones en su totalidad, adicionalmente desde su construcción no presentan ni contemplan un plan de mantenimiento que garantice la disminución de los efectos de futuras inundaciones. Por ejemplo, en el 2004 hubo una inundación nuevamente en la ciudad por el desbordamiento del río Zapote (La Nación, 2004). El caso más dramático ocurrió en noviembre de 2016 con la llegada del huracán Otto, el cual dejó víctimas mortales y millonarias pérdidas en infraestructura pública (puentes y caminos) y cultivos. Las lluvias acumuladas provocaron la formación de flujos de lodo y detritos en los ríos Canalete, Bijagua, Higuerón, y parte alta del Zapote, generando una máxima avenida extraordinaria en el río Zapote, la cual afectó sitios sin registro histórico de anegamiento flujos lodo o detritos (Sánchez, 2016).

En este punto, y antes de entrar en materia sobre el plan regulador que se había establecido para el cantón, que lamentablemente no fue atendido, es importante hacer hincapié en dos aspectos puntuales. Por un lado, comprender que el pueblo nació y se desarrolló "de la mano" con el río y que producto de esta coexistencia se creó un vínculo y un conjunto 
Gustavo Barrantes-Castillo José Francisco Valverde-Calderón Luis Sandoval-Murillo Arvin Romero-Romero

The potential contribution of the Territorial Regulatory Plan to offset the disaster take place in the

City of Upala, Province of Alajuela, Costa Rica, associated with the passage of Hurricane Otto

de conocimientos bioculturales que trascienden los aspectos meramente productivos.

Por ejemplo, hasta hace pocos años, en el marco de las celebraciones del 12 de octubre eran populares las carreras en balsas que salían del puente de Canalete hasta el puente que está en la salida de Upala hacia Guatuso.

Por otro lado, esa misma coexistencia había marcado lo que podríamos denominar un "límite de tolerancia", es decir, aunque el río se salía e inundaba algunas calles del centro de la ciudad, la gente había aprendido a "convivir" con esa realidad, por lo demás común en una región donde las lluvias intensas y los temporales son frecuentes.

Lo que aconteció con el huracán Otto tuvo una dimensión superior a toda experiencia anterior de los habitantes de Upala, quienes, con base en sus vivencias previas, se prepararon para enfrentar los fuertes vientos, sin tener noción de los efectos que podrían causar las intensas lluvias que se pronosticaban.

\section{Aporte del Plan Regulador en el conocimiento del riesgo de inun- daciones en la Ciudad de Upala}

Entre el 2008 y 2013 la Universidad Nacional (UNA), a través de la Escuela de Ciencias Geográficas, desarrolló los Planes Reguladores Upala, Guatuso y Los Chiles, con financiamiento de Cooperación Española por ф150 millones. Ninguno de estos productos logró alcanzar las aprobaciones por razones fundamentalmente políticas.

En el caso del Plan de Upala, la UNA entregó a la municipalidad los documentos establecidos en por el Instituto Nacional de Vivienda y Urbanismo (INVU) y la Secretaría Técnica Nacional Ambiental (SETENA), los cuales fueron aprobados por el Concejo Municipal.

Sin embargo, la municipalidad no realizó los trámites para su revisión y aprobación por parte de estas instancias, debido a los conflictos que ocasionó la zonificación de usos del suelo propuesta. En este sentido se produjo un rechazo del sector comercial a la propuesta, ya que, de acuerdo con los estudios realizados en las etapas de recopilación de la información, diagnóstico, pronóstico y propuesta, y de forma paralela, la incorporación de la variable ambiental en los Planes Reguladores de acuerdo con el decreto No. 32967-MINAE, el cuadrante urbano actual se localiza en una zona catalogada como de inundación, incluso así constaba en la 
información oficial aportada por la Comisión Nacional de Prevención de Riesgos y Atención de Emergencias (CNE). Esa situación generó conflictos entre los comerciantes y la municipalidad, lo que a la postre evitó que continuara el trámite de aprobaciones respectivo.

De acuerdo con la ECG-UNA (2012a) en el diagnóstico ambiental del plan regulador, se evidencio que existían 1.309 edificaciones en riesgo de inundación en los centros poblados de Upala, de las cuales 930 eran residencias, 295 comercios y entidades públicas y 84 otro tipo de estructuras (Cuadro 1).

Esta situación, llevó a proponer en el reglamento de zonificación, restringir las nuevas construcciones en las áreas con amenaza de inundación, trasladar los edificios de instituciones públicas a zonas seguras y en la medida de lo posible ir trasladando el área comercial del distrito central de ese cantón hacia las áreas seguras de la ciudad (ECG-UNA, 2012b) (Mapa 3).

De igual modo, el reglamento de zonificación propuesto refiere a lo establecido en la Ley de Planificación Urbana N4240, en el artículo 58 , donde se establece que las municipalidades no permitirán obras de construcción en tanto lo vede alguna limitación impuesta por reserva uso público o una declaratoria formal de inhabitabilidad del área, motivada en renovación urbana o protección contra inundaciones, derrumbes y otros peligros evidentes

El diagnóstico ambiental realizado por el plan regulador evidenció la presencia de dos tipos de inundaciones: la primera asociada con las zonas más planas (pendientes menores al 15\%), que abarca un $11.7 \%$ del territorio total del Cantón. Estas zonas corresponden con las llanuras de inundación de los ríos Zapote, Chimurria, Pizote, Caño Negro y Guacalito.

Entre los poblados ubicados en esta zona están: Upala Centro (mapa 4), Canalete, Rosario, Montecristo, San Judas, San Isidro (río Zapote), Santo Domingo, Chimurria Arriba, Chimurria Abajo, Colonia Puntarenas (río Chimurria), San José, Cuatro Bocas, Porvenir (río Pizote), San Jorge (río Caño Negro), Las Brisas, Santa Clara y Moreno Cañas (río Guacalito).

La segunda zona corresponde con inundación urbana (anegamiento), asociada principalmente al deficiente sistema de drenaje en el centro poblado sobre un relieve suave, lo que dificulta su evacuación. Es importante resaltar que la implementación de medidas de mitigación como la construcción de un canal de desagüe para desviar el agua y reducir el 
Gustavo Barrantes-Castillo José Francisco Valverde-Calderón Luis Sandoval-Murillo Arvin Romero-Romero The potential contribution of the Territorial Regulatory Plan to offset the disaster take place in the City of Upala, Province of Alajuela, Costa Rica, associated with the passage of Hurricane Otto

Mapa 3. Tipo de uso en el área susceptible a inundaciones según el Plan Regulador propuesto en 2012.
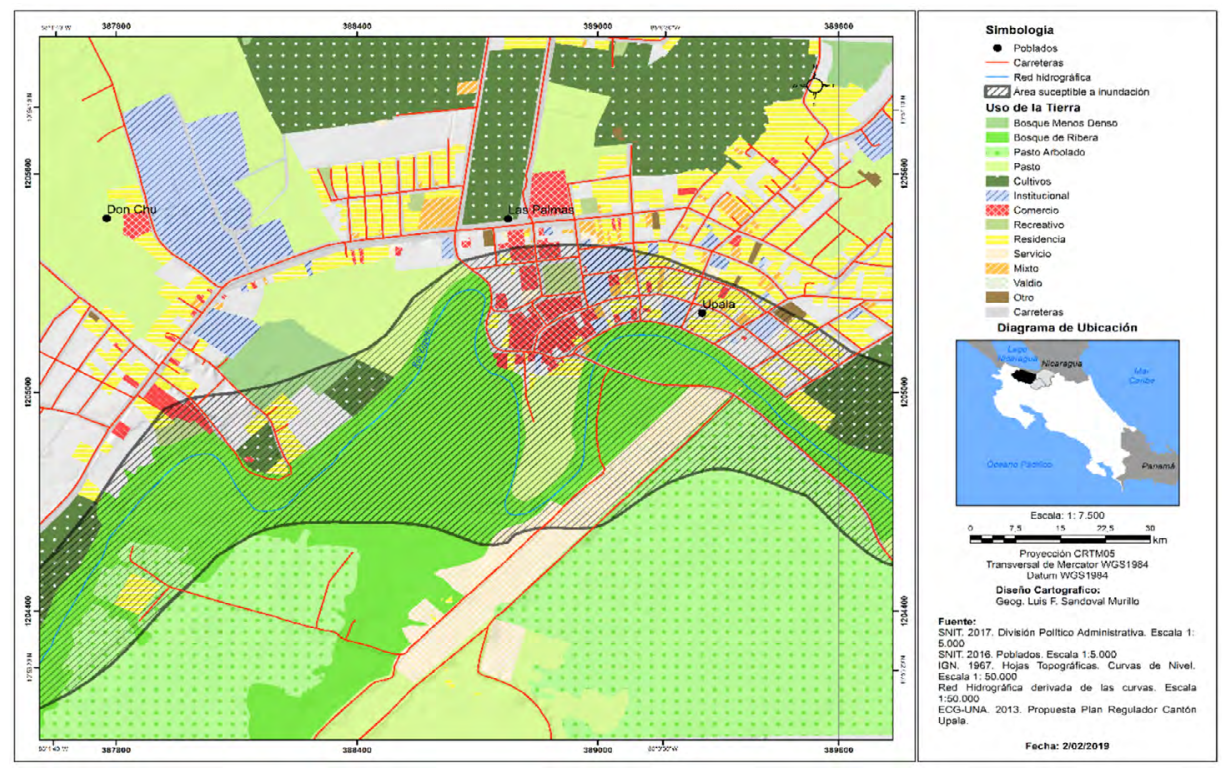

Fuente: Elaboración propia a partir ECG-UNA (2012c)

Cuadro 1. Cantidad de predios por tipos de usos en el área susceptible a inundación según el plan regulador propuesto en 2012

\begin{tabular}{|c|c|}
\hline Cantidad de predios por tipos de usos \\
\hline Uso & Cantidad de predios \\
\hline Transporte - Almacenaje & 6 \\
\hline Terreno Baldío & 17 \\
\hline Servicio & 58 \\
\hline Salud & 3 \\
\hline Residencial & 196 \\
\hline Religioso o culto público & 5 \\
\hline Recreativo - Deportivo & 3 \\
\hline Otro & 8 \\
\hline Mixto & 9 \\
\hline Gubernamental público & 15 \\
\hline Explotación agropecuaria & 3 \\
\hline Educación y cultura & 2 \\
\hline Comercial & 76 \\
\hline
\end{tabular}

Fuente: Elaboración propia a partir ECG-UNA (2012c) 
caudal río Zapote frente al poblado, así como la construcción de un dique de contención, obras desarrolladas en la década de los 90, son factores que han reducido el efecto de inundaciones anteriores. Dichas obras, desde su construcción no presentan ni contemplan un plan de mantenimiento que garantice la disminución de los efectos de futuras inundaciones con características superiores a las registradas para el huracán Juana en 1988, que afectó en su totalidad el área urbana de Upala, Comisión Nacional de Emergencias (CNE, 1988).

En el proceso de aprobación del plan se requiere cumplir con la Viabilidad Ambiental que otorga la SETENA, para lo cual se debe seguir la metodología conocida como IFAs según decreto ejecutivo 32967, por medio de índices de Amenazas Naturales.

De acuerdo con al diagnóstico ambiental del Plan Regulador (ECGUNA, 2012c), las inundaciones son el mayor riesgo en la formación de origen aluvial (Planicie aluvial con influencia del Lago de Nicaragua). Como resultado del indicador de amenaza, en el plan regulador se establece una "Zona de Riesgo por Inundación (ZRI)" (Mapa 4).

Los lineamientos establecidos en el reglamento de zonificación realizado por la Escuela de Ciencias Geográficas indicaban que era necesario regular la construcción de estructuras y viviendas, en las zonas que recurrentemente resultaban inundadas. Entre las recomendaciones propuestas estaban:

1. En las comunidades normalmente afectadas, mantener un monitoreo técnico de los cauces cercanos, ya que el cambio en la morfología del cauce puede generar mayor erosión lateral del mismo entre otras. Establecimiento de actividades relacionadas al control de la erosión como la preservación de la vegetación ya que las raíces de las plantas son capaces de retener el suelo.

2. Generar o fortalecer planes de emergencia en las zonas normalmente afectadas.

3. Definir la zona de control de inundaciones para el almacenamiento de agua que proviene de la precipitación y su liberación gradual por escorrentía.

4. Permitir el transporte por agua de bienes y pasajeros.

5. Protección de la fauna al constituirse en hábitats que mantienen altas diversidades de vida silvestre. 
Gustavo Barrantes-Castillo José Francisco Valverde-Calderón Luis Sandoval-Murillo Arvin Romero-Romero The potential contribution of the Territorial Regulatory Plan to offset the disaster take place in the City of Upala, Province of Alajuela, Costa Rica, associated with the passage of Hurricane Otto

\section{Mapa 4. Ubicación del área inundable en relación con la Ciudad de Upala.}

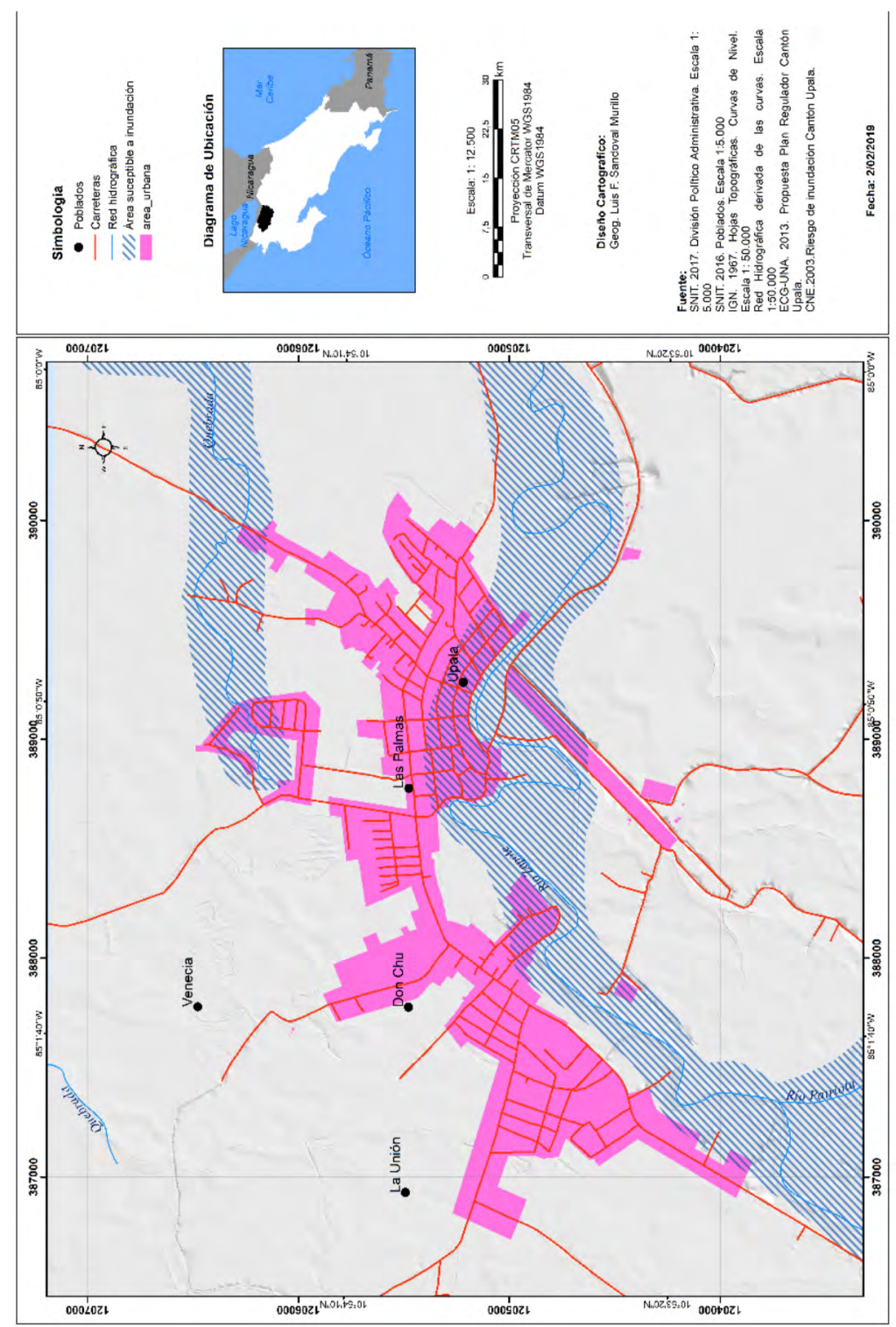

Fuente: Elaboración propia a partir ECG-UNA (2012c). 
6. Permitir el turismo controlado para observación de la vida silvestre y sus paisajes y la práctica de pesca de subsistencia.

En el reglamento de zonificación propuesto (ECG-UNA, 2012e), lo más significativo de la zona de riesgo a inundación, en cuanto al uso permitido, es el utilizar esta zona para el control de inundaciones por medio del almacenamiento de agua que proviene de eventos extremos, para su liberación gradual como escorrentía.

En este reglamento los denominados usos no conformes comprenden actividades que generen deforestación, contaminación física y química, la extracción indiscriminada de fauna y flora y cualquier otra actividad que ponga en riesgo infraestructura y vidas humanas. En esta última restricción se puede deducir que no se debe hacer un uso en infraestructura de viviendas, comercio y servicios, pero sin declararlo explícitamente, quizá por el peso que esta zona tiene desde punto de vista comercial y administrativo.

Así mismo, en la propuesta de zonificación, en cuanto a las zonas de protección de ríos y quebradas (ARTÍCULO 121), se plantea regular cualquier tipo de infraestructura, preservar y mejorar las condiciones del recurso hidrológico del Cantón (aguas superficiales y subterráneas, según lo estipulado en los artículos 33 y 34 de la Ley Forestal), específicamente en aquellas áreas de estas zona que presenten inundaciones recurrentes, no se autorizará ningún tipo de construcción a futuro, (ECG-UNA, 2012f).

De acuerdo con lo establecido en el reglamento de desarrollo sostenible en el artículo 19 (ECG-UNA, 2012g), se consideran una serie de lineamientos ambientales generales para la gestión de las amenazas naturales y la gestión del riesgo, resultado del análisis de la dimensión ambiental de los Efectos Acumulativos y el informe de Análisis del Alcance Ambiental como elementos técnicos que sustentan la variable ambiental de la Propuesta de Zonificación del Plan Regulador del Cantón de Upala, los que están directamente relacionados con el tema de las inundaciones fueron:

1. La municipalidad debe identificar, delimitar, restringir y prohibir el desarrollo de infraestructura en zonas con riesgo naturales de inundación, derrumbes y otros peligros evidentes, en conformidad con el artículo 58 de la Ley de Planificación Urbana No 4220.

2. La municipalidad en coordinación con la Comisión Nacional de Emergencias y el Comité Local de Emergencias, debe establecer planes y fortalecer herramientas de planificación e implementación 
Gustavo Barrantes-Castillo José Francisco Valverde-Calderón Luis Sandoval-Murillo Arvin Romero-Romero The potential contribution of the Territorial Regulatory Plan to offset the disaster take place in the City of Upala, Province of Alajuela, Costa Rica, associated with the passage of Hurricane Otto

de medidas de mitigación con los comités locales de prevención ante riesgos por distrito.

3. La municipalidad en coordinación con el Comité Local de Emergencias debe identificar las capacidades de las personas expuestas a riesgos naturales (líderes comunales) y recursos locales que faciliten la atención de emergencias en comunidades como Bijagua, Upala, Yolillal, San José Pizote, Aguas Claras y Dos Ríos, con el propósito de aprovechar los factores positivos como localización de lugares seguros y la ejecución de sistemas de alerta temprana.

4. La municipalidad en coordinación con el Comité Local de Emergencias debe implementar programas de educación y comunicación sobre los riesgos naturales que se presentan en el cantón por medio de la radio local, la celebración de actividades culturales a nivel de cada comunidad e instituciones educativas de primaria y secundaria del cantón.

5. La municipalidad en coordinación con SETENA debe velar por que la ubicación de futuros proyectos urbanísticos y el desarrollo de infraestructura en el cantón, contemplen la realización de estudios detallados a nivel ambiental, donde se desarrolle la valoración de los posibles riesgos naturales que podrían afectar dichas actividades.

6. Establecer un plan de mantenimiento de infraestructura de mitigación ante riesgos naturales, principalmente en el sector de Upala sobre el dique y el canal construido sobre el río Zapote para garantizar su funcionalidad.

7. Crear escenarios posibles de afectación de riesgo o combinación de estos que afecten las actividades humanas, principalmente en el distrito de Bijagua y Upala donde se contempla una serie de riesgos ambientales como flujo de lahares e inundaciones.

\section{Limitaciones de la propuesta de Plan Regulador en el caso de la Ciudad de Upala}

El equipo de la UNA que estuvo al frente del desarrollo del plan, al igual que algunos especialistas en el tema, han especulado sobre la posible disminución del desastre causado por la inundación de haberse aprobado e implementado el Plan Regulador propuesto. 
Gustavo Barrantes-Castillo José Francisco Valverde-Calderón Luis Sandoval-Murillo Arvin Romero-Romero La potencial contribución del Plan Regulador Territorial frente al desastre en la Ciudad de Upala, Provincia de Alajuela, Costa Rica, asociado al paso del Huracán Otto

No obstante, no se había realizado un contraste entre el área inundada durante el evento con la zonificación propuesta en el plan. En esta sección se compara las zonas con restricción por riesgos naturales, específicamente el área con amenaza de inundación que se trabajó en dicho plan (Mapa 5), con la zona inundada en la ciudad y sus alturas desarrollada en esta investigación.

Mapa 5. Zonificación propuesta en el Plan Regulador propuesto en 2012.
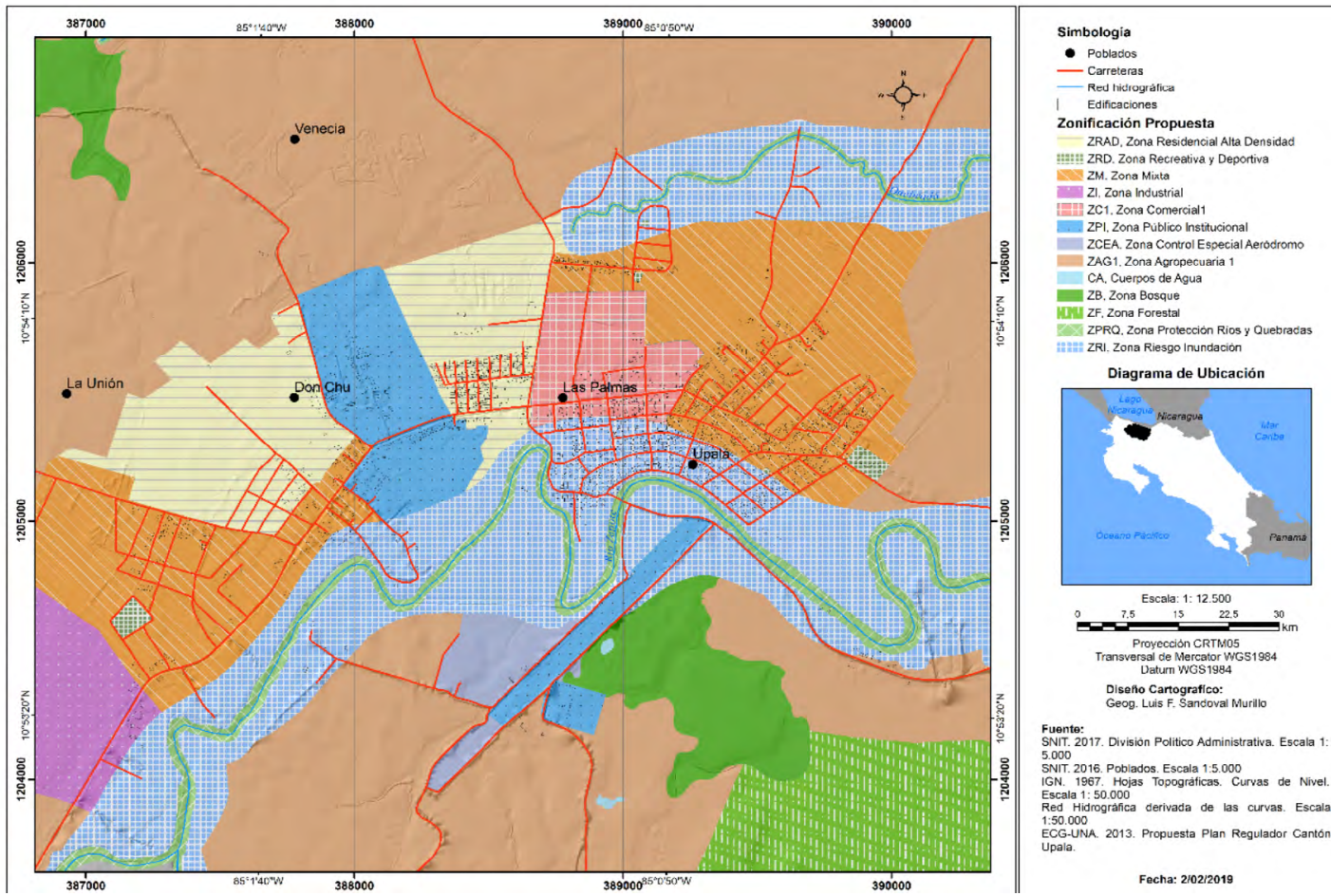

Fuente: Elaboración propia.

\section{Conflicto generado a nivel de la comunidad por la propuesta de} la zona de riesgo de inundación

La zona de riesgo de inundación demarcada en la propuesta de zonificación por parte del equipo técnico de la ECG-UNA, genero la oposición del sector comercial y de vecinos, disconformidad que se evidencia en los talleres realizados el 5 y 6 de julio del 2012 en la comunidad de Upala sobre la propuesta de zonificación de usos del suelo. 
Gustavo Barrantes-Castillo José Francisco Valverde-Calderón Luis Sandoval-Murillo Arvin Romero-Romero The potential contribution of the Territorial Regulatory Plan to offset the disaster take place in the City of Upala, Province of Alajuela, Costa Rica, associated with the passage of Hurricane Otto

Los participantes se enfocaron prioritariamente es esta zona propuesta, recomendando revisar y reconsiderar en todo el cantón estas zonas, donde se citan de forma textual las siguientes observaciones (ECG-UNA, 2012h, pp. 8 -11):

1. Canalete se indica como zona con riesgo de inundación sin embargo nunca se ha inundado ni siquiera cuando paso el huracán Juana que es el evento más extremo que hemos tenido en los últimos veinte años; en ese momento el caudal del río Zapote llegó, a más o menos, dos metros antes de las vigas del puente. Canalete ni siquiera se inunda en aguaceros de gran intensidad y de larga duración.

2. En el Rosario, la zona marcada es demasiado ancha, igual que Canalete, no tiene registro de inundación ni de eventos extremos.

3. Se continúan marcando las zonas con riesgo de inundación, que ya no son vulnerables con las obras de mitigación que en su momento se hicieron en el Río Zapote, tal como: el canal y el muro. O sea, no se están considerando los resultados que generaron estas obras, las cuales, a pesar de no darles mantenimiento, ya que el canal desde su construcción nunca se ha limpiado, sigue realizando la función para lo cual fue construido.

4. Si la información oficial que se está tomando es la que dispone la Comisión de Emergencia consideramos que dicha información no es verídica pues marcan zonas con Riesgo de Inundación donde ni siquiera un aguacero de larga duración ha inundado esos lugares.

5. El mapa que tiene disponible la Comisión Nacional de Emergencia en Internet difiere de los mapas de zonificación del Plan Regulador.

6. El evento extremo registrado en los últimos veinticinco años es el huracán Juana y no se registraron daños materiales ni humanos.

De las observaciones anteriores el equipo técnico de la ECG-UNA, estableció las siguientes respuestas para cada una de las consultas mencionadas, misma que se presentan de forma textual según el informe (ECGUNA, 2012h, pp. 8 - 11):

1. De acuerdo con los registros de la CNE, el último evento de inundación registrado en Canalete fue el 14 de diciembre de 1994, en donde se vieron afectadas 45 personas. Sin embargo, el área de riesgo de inundación es modificada (pero no eliminada), ya que se evidencian diferencias en la escala del mapa de la CNE (1:50.000) y la escala 
(1:25.000) en que el Equipo Técnico de la ECG de la UNA elaboró el mapa de zonificación propuesta, por lo que se hizo un ajuste a nivel de escala para que ambos mapas sean coincidentes.

2. De acuerdo con los registros de la CNE, el 3 de junio de 1999, el puente que comunica Gavilán con Agroindustrial Sur, fue arrasado por una crecida; se vieron afectadas 70 viviendas y 280 personas. La ZRI al margen derecho del Río Zapote se reduce en 800 metros, por condiciones de pendiente quedando en 200 metros, sin embargo; el margen izquierdo del río paralelo a la carretera se mantiene la misma área de inundación propuesta.

3. Las obras de mitigación tienen una vida útil limitada por lo que este tipo de obras no pueden ser consideradas por el Plan Regulador como permanentes en el tiempo, a menos de que existan planes de mantenimiento permanente. En este sentido, el equipo técnico está analizando legalmente como incorporar y reglamentar el mantenimiento de las obras de mitigación actuales y las futuras por lo que las áreas de inundación en el centro poblado se mantienen.

4. Para confirmar dicha afirmación, se realizó una investigación sobre los eventos registrados por la CNE desde 1968 a la fecha.

5. Los mapas de la CNE fueron elaborados a escala 1:50.000, y el de la zonificación propuesta a escala 1:25.000. De igual manera, debe aclararse que para establecer las ZRI además de considerar los mapas de la CNE, se realizó un estudio geológico específico para el Cantón.

6. De acuerdo con los registros de la CNE con el Huracán Juana, el 22 de octubre de 1988, se dio el desbordamiento del río Zapote, lo que afectó a toda la población del centro de Upala (aproximadamente 5.000 personas fueron evacuadas).

A pesar de la argumentación planteada en cada respuesta para las observaciones y consultas generadas en el taller, el descontento de los comerciantes y vecinos persistía generando que la municipalidad no procediera con el trámite ante las instancias correspondientes para su revisión en ese momento INVU Y SETENA. 
Gustavo Barrantes-Castillo José Francisco Valverde-Calderón Luis Sandoval-Murillo Arvin Romero-Romero

The potential contribution of the Territorial Regulatory Plan to offset the disaster take place in the

City of Upala, Province of Alajuela, Costa Rica, associated with the passage of Hurricane Otto

\section{La inundación en Upala y la Zona de Riesgo de Inundación esta- blecida en el Plana Regulador propuesto}

El 24 de noviembre de 2016 aconteció la mayor inundación registrada en la ciudad de Upala. El evento inició con 20 mil millones de litros de lluvia acumulada entre 4 a $5 \mathrm{~h}$, lo que disparó varios deslizamientos y flujos de lodo y roca de las paredes de fuerte pendiente, en la sección alta de la microcuenca, que impactan caminos, puentes y algunas viviendas en su recorrido hacia la llanura de inundación. Estos flujos provocaron el desbordamiento del río sobre su lecho extraordinario, generando una amplia zona de afectación desde Canalete hasta Upala (Sánchez, 2016).

A pesar de que las autoridades nacionales, incluido el presidente de la república Luis Guillermo Solís solicitó evacuar el centro de Upala dos días antes del impacto de Otto (Murillo \& Miranda, 2016), el Comité Local de Emergencias y en particular el alcalde de Upala, quien la presidia, en este entonces Juan Acevedo, asumieron esta situación como una inundación común del río Zapote, incluso el alcalde aceptó que antes de evacuar la ciudad optaron por hacer llamados a la población por medio de perifoneo para que estuviese atenta (Hernández \& Rodríguez, 2017).

De acuerdo con la sistematización de la experiencia realizada por Hernández \& Rodríguez (2017), la población no creyó que la inundación tomara las proporciones que finalmente tuvo o no se enteró de la gravedad de la situación y los tomó por sorpresa.

La experiencia indicaba que el centro comercial y las áreas más próximas al río fueran las que recibieran las mayores alturas del agua. De acuerdo con la reconstrucción de los niveles máximos del agua realizados en esta investigación, las mayores alturas se registraron también en otros sitios.

El centro de la ciudad presentó alturas de entre $1 \mathrm{~m}$ y $1,5 \mathrm{~m}$ que afectaron el parque central, el local de la Cruz Roja, el edificio de la Municipalidad y la Escuela. Así mismo, en las afueras de la ciudad se presentó un segundo máximo sobre el barrio Don Chu donde se registraron alturas de inundación de entre $1 \mathrm{~m}$ y 1,90 m (Mapa 6).

Es importante señalar que estos niveles se alcanzaron pese a que el río había desbordado parte del caudal en lugares como Canalete y el Rosario, donde también hubo importante afectación de viviendas. 
Como se puede apreciar en el Mapa 6 las mayores alturas de las aguas de la inundación se presentaron en las proximidades a la ribera del río Zapote; en las áreas cercanas al Hospital y Colegio Técnico; sobre el barrio Don Chu; el barrio Verdún; entre los Barrios Venecia y el Real; y en la Ciudad por el parque y la zona comercial. Por el contrario, el área que registró menores alturas fue el sector suroeste de la ciudad (próximo a la estación de bomberos).

$\mathrm{Al}$ observar la distribución del área inundada se puede deducir que el río desborda su caudal antes de llegar a la ciudad encontrando una avenida para transitar, de suroeste a noreste, a través de terrenos agrícolas de baja altitud que se localizan entre cuadrante urbano (calle 4) y la calle donde se ubica el colegio técnico.

De esta forma una parte importante del caudal logra atravesar sobre el barrio Don Chu, para desaguar en una quebrada localizada al norte de la ciudad, entre el barrio Venecia y el barrio Real (Mapa 6). De esta forma, el flujo principal que sale del cauce rodea la ciudad en su parte más profunda.

De acuerdo con la distribución observada, la escuela nueva que fue reubicada recibió una altura máxima de $0,56 \mathrm{~m}$ (Figura 2), no obstante, en la ubicación anterior frente al parque, la escuela en funciones en este momento registró una altura de $1.37 \mathrm{~m}$, lo que representa más del doble que en el nuevo emplazamiento (Figura 3).

Al contrastar la zona de ZRI con las isolíneas de máxima altura alcanzada por las aguas de inundación, coinciden en las áreas de proximidad al curso fluvial donde se registraron las mayores alturas. No obstante, un área en esta misma condición ubicada al oeste de la Estación de Bomberos registro la menor altura.

La explicación a este hecho podría estar en la presencia de un dique que se construyó para proteger la ciudad de las inundaciones, mismo que contuvo el flujo, lo que a su vez pudo contribuir a aumentar la altura del agua en otros puntos como el parque central (Figura 4, Mapa 6).

Luego de la inundación los noticieros se enteraron de la propuesta del plan regulador y se instaló la idea de que si el plan regulador hubiese sido aprobado en aquel momento (4 años antes de la inundación), la cantidad de pérdidas materiales y de vidas humanas hubiese resultado menor. 
Gustavo Barrantes-Castillo José Francisco Valverde-Calderón Luis Sandoval-Murillo Arvin Romero-Romero The potential contribution of the Territorial Regulatory Plan to offset the disaster take place in the City of Upala, Province of Alajuela, Costa Rica, associated with the passage of Hurricane Otto

Mapa 6. Reconstrucción de las máximas alturas alcanzadas por la inundación 24 de noviembre de 2016

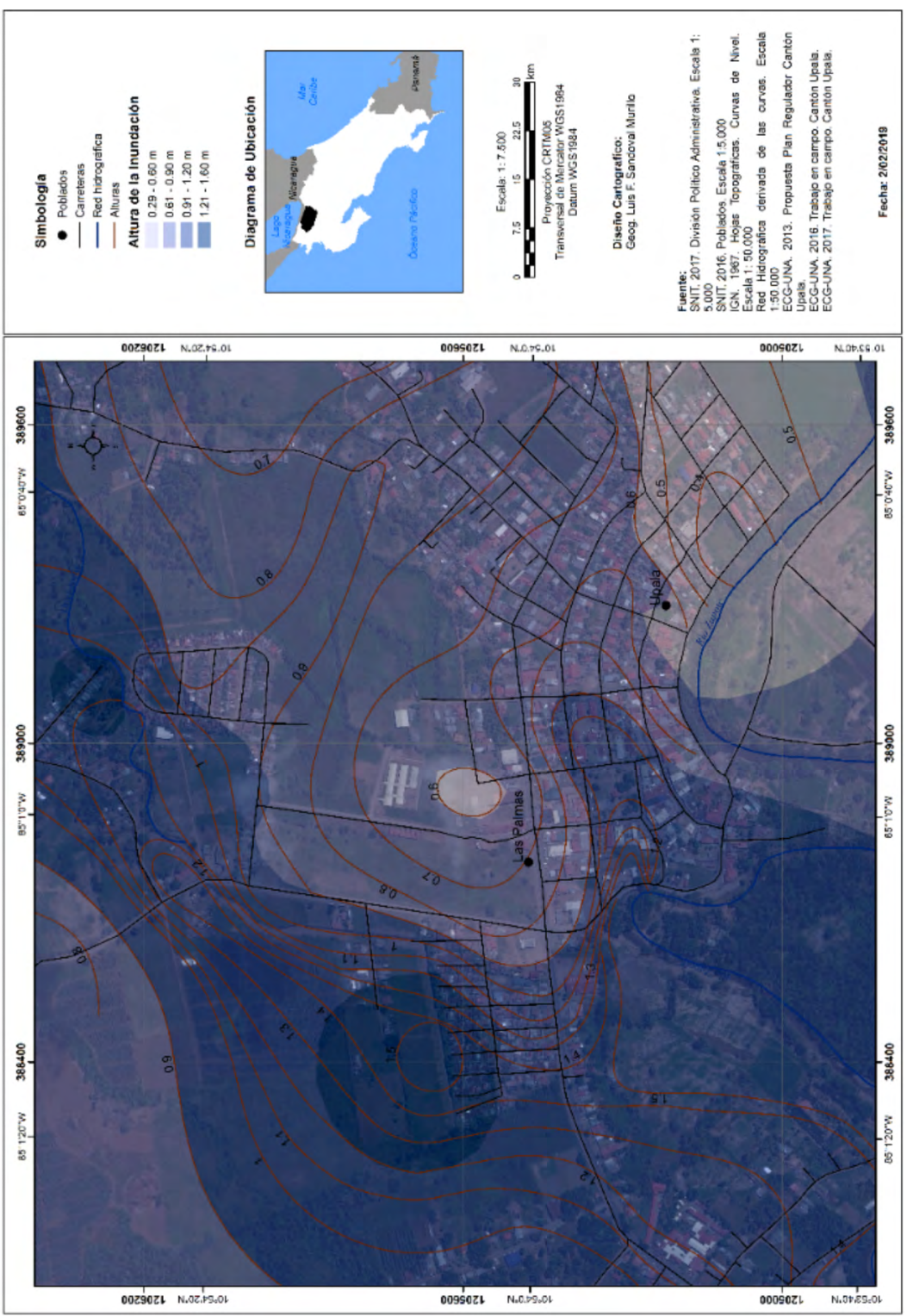

Fuente: Elaboración propia. 
Gustavo Barrantes-Castillo José Francisco Valverde-Calderón Luis Sandoval-Murillo Arvin Romero-Romero La potencial contribución del Plan Regulador Territorial frente al desastre en la Ciudad de Upala, Provincia de Alajuela, Costa Rica, asociado al paso del Huracán Otto

Figura 2. Nivel máximo alcanzado por la inundación en el emplazamiento de la nueva escuela de Upala.

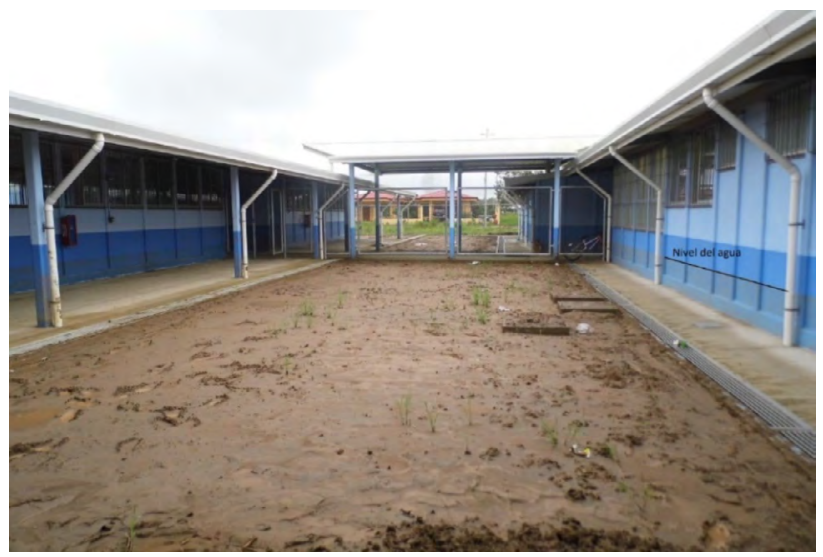

Fuente: Elaboración propia

Figura 3. Nivel máximo alcanzado por la inundación en la escuela frente al parque de Upala

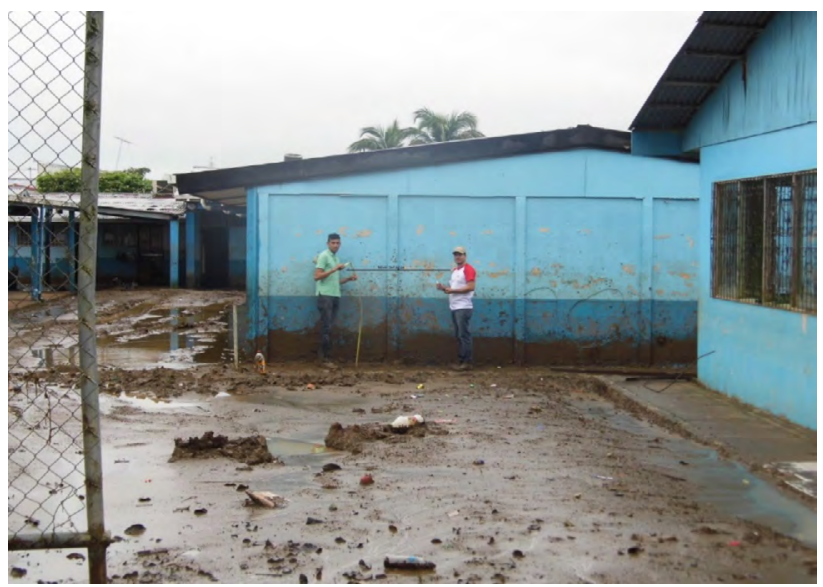

Fuente: Elaboración propia 
Figura 4. Dique construido en el sector sureste de la ciudad contiguo al río Zapote.

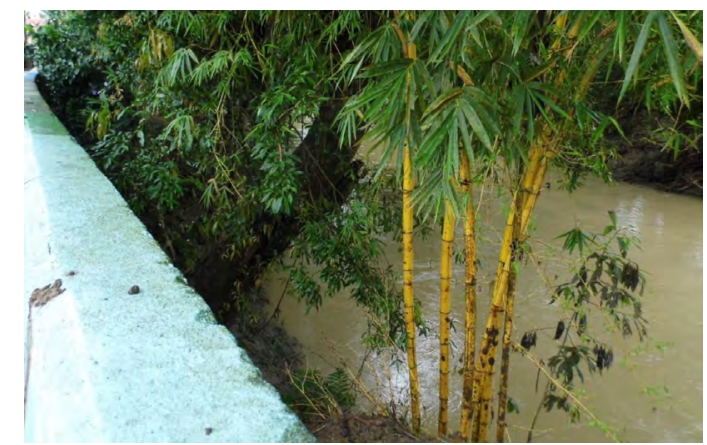

Fuente: Elaboración propia

Sobre esto, hay que analizar dos aspectos, el primero que con la aprobación del plan no viene aparejado un cambio automático en el uso del suelo, lo que significa que no se habría dado un cambio en el uso del suelo, pero que, si se pudo haber evitado la construcción de nuevas edificaciones en el área con propensión a inundaciones, en otras palabras, el beneficio de la zonificación propuesta apenas habría tendido algún efecto en el centro de la ciudad.

No obstante, de acuerdo con lo indicado en los reglamentos, es posible que se hubiese desarrollado un mecanismo de atención de emergencias en caso de inundaciones como un Sistema de Alerta Temprano (SAT). Al menos esto era una aspiración emanda de los reglamentos, que en otros lugares previamente identificados como sitios de riesgo no se ha alcanzado.

El otro aspecto sobre la propuesta de usos del suelo y quizá el más relevante en cuanto a la inundación ocurrida, es el uso de suelo propuesto en las áreas donde se registraron elevados niveles de inundación lejos del cauce, específicamente en el corredor que se formó de suroeste a noreste, entre el Río Zapote, el Barrió Don Chu y el Barrio Venecia (mapa 6).

En esta área el uso de suelo propuesto es Zona Residencial de Alta Densidad y al sur una sección de la Zona Público Institucional (mapa 7). En otras palabras, se hubiese autorizado la construcción de viviendas e infraestructura pública en el área donde se alcanzaron las mayores alturas lejos del cauce. 
Gustavo Barrantes-Castillo José Francisco Valverde-Calderón Luis Sandoval-Murillo Arvin Romero-Romero La potencial contribución del Plan Regulador Territorial frente al desastre en la Ciudad de Upala, Provincia de Alajuela, Costa Rica, asociado al paso del Huracán Otto

Mapa 7. Zonificación propuesta y alturas máximas alcanzadas por la inundación 24 de noviembre de 2016

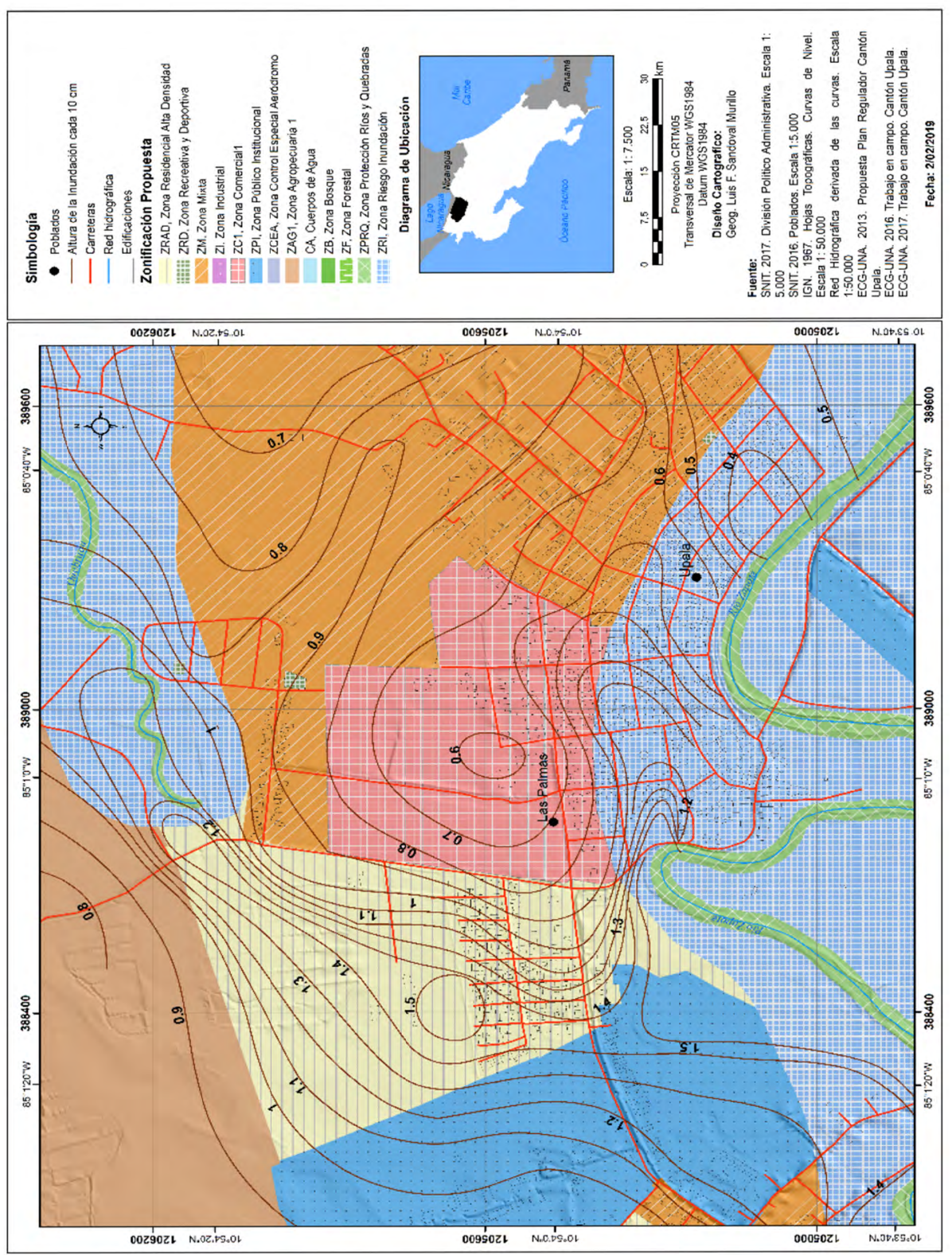

Fuente: Elaboración propia 
Gustavo Barrantes-Castillo José Francisco Valverde-Calderón Luis Sandoval-Murillo Arvin Romero-Romero The potential contribution of the Territorial Regulatory Plan to offset the disaster take place in the City of Upala, Province of Alajuela, Costa Rica, associated with the passage of Hurricane Otto

Los autores desean dejar en claro que este es un evento extremo y que la planificación física del territorio no se realiza con base en el peor escenario posible. Por otro lado, las condiciones previas al evento, como la ocurrencia de un sismo (5.4 Mw) que inestabilizó las laderas de la cuenca alta del río Zapote (Sánchez, 2016), sumado a la cantidad de lluvia acumulada en poco tiempo con el paso del huracán, crearon condiciones de un caudal con alta concentración de sedimentos (suelo, rocas, árboles) lo que generó un flujo con condiciones reológicas particulares que le permitieron un comportamiento atípico en cuanto a su desplazamiento y altura sobre el terreno, difíciles de haber sido previstas.

No obstante, en un contexto de Cambio Climático los eventos hidrometeorológicos que se consideran extremos pueden ir aumentando su frecuencia, por lo que este tipo de escenarios debe ser considerado a la hora de hacer Ordenamiento Territorial en Costa Rica, debido a la disminución el tiempo de retorno de los eventos que actualmente son extremos, esto expondría a más población e infraestructura a la ocurrencia de inundaciones periódicas.

\section{Conclusiones}

Los habitantes de la Ciudad de Upala tienen una relación histórica con el Río Zapote marcada al principio como una vía navegable que facilitaba la comunicación y el transporte de mercancías. Actualmente este emplazamiento le representa un riesgo constante de inundaciones que ha sido incorporado en la cultura por lo que el Upaleño ha desarrollado alta resiliencia frente a las inundaciones.

La trayectoria seguida por el Huracán Otto proveyó una cantidad extraordinaria de precipitaciones que provocó una inundación inédita que rebasó la expectativa de los lugareños, quienes actuaron conforme a su percepción de la amenaza, más preocupados por la velocidad del viento que por la altura y velocidad de las aguas de la inundación.

Las aguas de la inundación alcanzaron las mayores alturas, como era de esperar, en las cercanías al cauce fluvial, no obstante, un segundo flujo de agua parece haber atravesado el terreno entre el río y una quebrada localizada al norte de la ciudad, atravesando el residencial Don Chu. Esto se deduce del modelo de alturas máximas alcanzadas por la inundación 
que fue construido con datos de campo a partir de las marcas dejadas por la inundación.

El Plan Regulador propuesto en el 2012, estableció una zona con propensión a inundaciones donde restringe los usos del suelo, esta área se corresponde con parte del centro de la ciudad donde se registraron máximos de altura de inundación, como el parque, la escuela y la municipalidad, no obstante, incluyó un sector al sureste de la ciudad que recibió la menor altura del agua, posiblemente como resultado de la presencia de un dique que cambió la distribución de las aguas.

El segundo sector con mayores alturas que atraviesa los terrenos anteriores a la ciudad, pasando por el barrio Don Chu, fue catalogado en el Plan Regulador propuesto para el 2012 como un área de uso residencial e institucional, lo que pudo aumentar el riesgo si se hubiesen seguido los lineamientos del plan.

Este hecho, se debe a que la planificación física del territorio no se hace con base en el peor escenario posible, además de las particularidades del evento que generó un flujo cargado de sedimentos que le permitió, al ir colmatando el cauce, alcanzar gran altura de agua en sitos donde no era de esperar según el análisis de la pendiente del terreno.

Lo sucedido durante la inundación y lo documentado en esta investigación, debe ser incorporado en el nuevo Plan Regulador o en el Proceso de Reconstrucción, debido a que, en un contexto de Cambio Climático, los eventos extremos pueden volverse más recurrentes, de esta forma se podría hacer planificación urbana y prospección del riesgo incorporando las lecciones aprendidas de esta tragedia.

\section{Agradecimientos}

Un agradecimiento especial a la Rectoría de la Universidad Nacional por el financiamiento parcial de esta investigación, considerada un aporte al conocimiento de este tipo de desastres para contribuir en su prevención. Así mismo, se agradece al Máster Adolfo Quesada Román por su contribución en el levantamiento de datos durante la primera campaña de campo realizada. 
Gustavo Barrantes-Castillo José Francisco Valverde-Calderón Luis Sandoval-Murillo Arvin Romero-Romero The potential contribution of the Territorial Regulatory Plan to offset the disaster take place in the City of Upala, Province of Alajuela, Costa Rica, associated with the passage of Hurricane Otto

\section{Referencias}

Archivo Nacional de Costa Rica (ANCR). (1921). Secretaría de Fomento. Documento $\mathrm{N}^{\circ} 004317$.

Brown, D. P. (2017). Hurricane Otto. NOAA. Obtenido de https://www. nhc.noaa.gov/data/tcr/AL162016_Otto.pdf

Chinchilla, E. (1987). Atlas cantonal de Costa Rica. San José: IFAM.

Comisión Nacional de Emergencias (CNE). (2003). Amenazas naturales cantón de Upala. Mapa de amenazas naturales potenciales cantón de Talamanca. Recuperado el 30 de mayo del 2009 en: https://www. cne.go.cr/reduccion_riesgo/mapas_amenzas/mapas_de_amaneza/ alajuela/Upala.pdf

Comisión Nacional de Emergencias (CNE). (2012). Histórico de desastres en Costa Rica. Recuperado de: https://www.bvs.sa.cr/ambiente/4923.pdf

Comisión Nacional de Emergencias (CNE). (2017). Plan general de la emergencia ante la situación provocada por el paso del huracán Otto por el territorio costarricense. San José.

Comisión Nacional de Emergencias (CNE). (1988). Aspectos meteorológicos de la emergencia. Huracán Juana. San José. Costa Rica, pp. $1-21$.

Escuela de Ciencias Geográficas - Universidad Nacional (ECG-UNA). (2012). Diagnóstico Sociocultural, Económico, Turismo y Migración. Plan Regulador de Upala, pp. 1 - 226.

Escuela de Ciencias Geográficas - Universidad Nacional (ECG-UNA). (2012a). Diagnóstico Ambiental. Amenazas naturales. En Plan Regulador de Upala, pp. 45 - 48.

Escuela de Ciencias Geográficas - Universidad Nacional (ECG-UNA). (2012b). Reglamento de zonificación. Capítulo XV. Zona de Protección de Ríos y Quebradas (ZPRQ) y Capítulo XXVII. Zona Riesgo Inundación (ZRI). En Plan Regulador de Upala, pp. 1 - 82.

Escuela de Ciencias Geográficas - Universidad Nacional (ECG-UNA). (2012c). Diagnóstico Ambiental. Análisis de las unidades geomorfo-

lógicas cantón Upala. En Plan Regulador de Upala, pp. 13-38.

Escuela de Ciencias Geográficas - Universidad Nacional (ECG-UNA). (2012e). Reglamento de zonificación. Zona riesgo de inundación. 
Gustavo Barrantes-Castillo José Francisco Valverde-Calderón Luis Sandoval-Murillo Arvin Romero-Romero La potencial contribución del Plan Regulador Territorial frente al desastre en la Ciudad de Upala, Provincia de Alajuela, Costa Rica, asociado al paso del Huracán Otto

Usos permitidos y conformes. En Plan Regulador de Upala, pp. 1 $-82$.

Escuela de Ciencias Geográficas - Universidad Nacional (ECG-UNA). (2012f). Reglamento de zonificación. Capítulo XV. Zona de Protección de Ríos y Quebradas (ZPRQ). Artículo 121. En Plan Regulador de Upala, pp. 1-82.

Escuela de Ciencias Geográficas - Universidad Nacional (ECG-UNA). (2012g). Reglamento de desarrollo sostenible. Lineamientos ambientales generales para la gestión de amenazas naturales y la gestión del riesgo. Artículo 19. En Plan Regulador de Upala, pp. 1-115. Escuela de Ciencias Geográficas - Universidad Nacional (ECG-UNA). (2012h). Informe del 2do. taller de validación de las propuestas de zonificación del cantón de Upala con el CCCI ampliado y el Concejo Municipal. En Plan Regulador de Upala, pp. 8-11.

Hall, C. (1982). El café y el desarrollo histórico-geográfico de Costa Rica. San José, Costa Rica: Editorial Costa Rica.

Hernández, G. (2006). Mapa Climático de Costa Rica. Costa Rica: Universidad Nacional.

Hernández, J. \& Rodríguez, D. (2017). Resistiendo entre el barro: La Red de Mujeres Rurales de Costa Rica de Upala ante el Huracán Otto. Costa Rica: Curso Virtual Sistematización de experiencias .

Instituto Meteorológico Nacional. (2017). Huracán Otto: Informe técnico. San José. Recuperado de https://www.imn.ac.cr/ documents/10179/20909/Informe+IMN+Hurac\%C3\%A1n+Otto

Ley de planificación Urbana $N^{\circ} 4240$. Sistema Costarricense de Información Jurídica. Costa Rica. 15 de noviembre de 1968.

La Nación (2004). "Intensas lluvias inundan centro de Upala". Nación digital, 8 de diciembre. Accesible en: https://www.nacion.com/el-pais/intensas-lluvias-inundancentro-de-upala/SCACRVC3ERAKPFFA6Z52ID73OQ/ story/

Martínez, C. (1967). Apuntes sobre el urbanismo en el Nuevo Reino de Granada. Bogotá, Colombia. Talleres Gráficos del Banco de la República.

Murillo, Á. \& Miranda, H. (30 de Noviembre de 2016). ¿Por qué el huracán Otto azotó así a Upala? Semanario Universidad. 
Torres, M. \& Peters, G. (2013). "La colonización de una zona periférica en el agotamiento de la frontera agrícola nacional. El caso de Upala.1920-1950". Informe de Investigación. Escuela de Historia. Heredia, Costa Rica (sin publicar)

Sánchez, B. (2016). Informe técnico, afectaciones generadas en la zona norte de Costa Rica tras el paso del Huracán Otto, modelo geológico del evento extremo para los Cantones de Upala y Baga. San José: CNE.

Solórzano, V.W. (2005). "Poblamiento y colonización de la región norte de Costa Rica (1850-1955)". En, Samper Kutschbach, Mario. Compilador. Trayectorias y disyuntivas del agro en la Zona Norte de Costa Rica. $1^{\text {a }}$. Ed. - San José, Costa Rica: Lara Segura \& Asociados. 